\title{
Comparison of alternative arterial anastomosis site during liver transplantation when the recipient's hepatic artery is unusable
}

\author{
Jean Marie Beaurepaire ${ }^{1,2}$, Francesco Orlando ${ }^{1}$, Giovanni Battista Levi Sandri ${ }^{1}$, Caroline Jezequel ${ }^{3}$, \\ Edouard Bardou-Jacquet ${ }^{2,3,4}$, Christophe Camus ${ }^{4,5}$, Mohamed Lakehal ${ }^{1}$, Veronique Desfourneaux ${ }^{1}$, \\ Aude Merdrignac $^{1,2}$, Elodie Gaignard ${ }^{1,2}$, Alexandre Thobie $^{1}$, Damien Bergeat ${ }^{1,2}$, Bernard Meunier ${ }^{1,2}$, \\ Michel Rayar ${ }^{1,2,4}$
}

${ }^{1} \mathrm{CHU}$ Rennes, Service de Chirurgie Hépatobiliaire et Digestive, Rennes, France; ${ }^{2}$ Université Rennes 1, Faculté de Médecine, Rennes, France; ${ }^{3} \mathrm{CHU}$ Rennes, Service des Maladies du Foie, Rennes, France; ${ }^{4}$ INSERM, CIC 1414, Rennes, France; ${ }^{5}$ CHU Rennes, Service de Maladies Infectieuses et Réanimation Médicale, Rennes, France

Contributions: (I) Conception and design: M Rayar, JM Beaurepaire, GB Levi Sandri; (II) Administrative support: D Bergeat, C Camus, E BardouJacquet, M Lakehal, A Thobie, B Meunier, E Gaignard; (III) Provision of study materials or patients: M Rayar, JM Beaurepaire, GB Levi Sandri; (IV) Collection and assembly of data: JM Beaurepaire, F Orlando, GB Levi Sandri, V Desfourneaux, A Merdrignac, M Rayar, C Jezequel; (V) Data analysis and interpretation: M Rayar, JM Beaurepaire, GB Levi Sandri; (VI) Manuscript writing: All authors; (VII) Final approval of manuscript: All authors.

Correspondence to: Michel Rayar, MD. Service de Chirurgie Hépato-Biliaire et Digestif., CHU Pontchaillou, 35033 Rennes, France.

Email: michel.rayar@chu-rennes.fr.

Background: Few studies have analyzed outcomes of liver transplantation (LT) when the recipient hepatic artery (HA) was not usable.

Methods: We retrospectively evaluated the outcomes of LT performed using the different alternative sites to HA.

Results: Between 2002 and 2017, 1,677 LT were performed in our institution among which 141 (8.4\%) with unusable recipient HA were analyzed. Four groups were defined according to the site of anastomosis: the splenic artery (SA group, $n=26$ ), coeliac trunk (CT group, $n=12$ ), aorta using or not the donor's vessel (Ao group, $\mathrm{n}=91$ ) and aorta using a vascular prosthesis (Ao-P group, $\mathrm{n}=12$ ) as conduit. The median number of intraoperative red blood cell transfusions was significantly increased in the Ao and Ao-P groups (5, 5, 8.5 and 16 for SA, CT, Ao and Ao-P group respectively, $\mathrm{P}=0.002)$, as well as fresh frozen plasma $(4.5,2.5,10,17$ for the SA, CT, Ao and Ao-P groups respectively, $\mathrm{P}=0.001)$. Hospitalization duration was also significantly increased in the Ao and Ao-P groups (15, 16, 24, 26.5 days for the SA, CT, Ao and Ao-P groups respectively, $\mathrm{P}<0.001)$. The occurrence of early allograft dysfunction $(\mathrm{EAD})(\mathrm{P}=0.07)$ or arterial complications $(\mathrm{P}=0.26)$ was not statistically different. Level of factor $\mathrm{V}$, INR, bilirubin and creatinine during the $7^{\text {th }}$ postoperative days (POD) was significantly improved in the SA group. No difference was observed regarding graft $(\mathrm{P}=0.18)$ and patient $(\mathrm{P}=0.16)$ survival.

Conclusions: In case of unusable HA, intraoperative and postoperative outcomes are improved when using the SA or CT compared to aorta.

Keywords: Liver transplantation (LT); hepatic artery (HA); arterial anastomosis; splenic artery (SA)

Submitted Jan 06, 2020. Accepted for publication May 13, 2020.

doi: $10.21037 / \mathrm{hbsn}-20-10$

View this article at: http://dx.doi.org/10.21037/hbsn-20-10 


\section{Introduction}

Liver transplantation (LT) is the best treatment for endstage liver disease and primary liver tumor. Despite surgical, medical and radiological improvements in diagnosis and treatment, arterial anastomosis remains a challenge with an incidence of hepatic artery thrombosis (HAT) varying from $4 \%$ to $15 \%(1-3)$ with a significant impact on graft and patient outcomes $(4,5)$.

Arterial anastomosis is usually performed between the graft and the recipient's hepatic artery (HA). However, when the recipient's HA is unusable (owing to complete thrombosis, intimal dissection, small size or inadequate flow), alternative sites such as aorto-hepatic anastomosis with or without conduits $(6,7)$, coeliac trunk (CT) $(8,9)$ or splenic artery (SA) (10-12) are used.

To date, few studies have compared the intraoperative and postoperative outcomes of these different alternative sites. Consequently, the choice usually depends on the surgeon's experience or habits.

The aim of this study was to analyze and compare the outcomes of alternative anastomosis sites in case of unusable recipient HA during LT. We present the following article in accordance with the STROBE reporting checklist (available at https://hbsn.amegroups.com/article/view/10.21037/ hbsn-20-10/rc).

\section{Methods}

\section{Patient selection}

From January 2002 to December 2017, all adult LT or retransplantations performed in a high-volume LT center in which native recipient HA was not used $(n=146)$ were retrospectively analyzed. Patients with associated transplantation of another organ $(\mathrm{n}=1)$, transplanted with a split liver graft $(\mathrm{n}=2)$, pediatric donor $(\mathrm{n}=1)$ or donor after cardiac death $(\mathrm{n}=1)$ were excluded from the analysis (Figure 1).

Depending on the recipient site of arterial anastomosis and reconstruction technique, 4 groups were defined: (I) anastomosis on the SA (SA group) usually in a side-toend fashion; (II) on the CT (CT group); (III) on the aorta using or not the donor's vessel (Ao group) or (IV) using a vascular prosthesis (Ao-P group) as conduit. No patients had previous splenectomy.

Patients transplanted using the recipient HA $(n=1,531)$ were also analyzed as the reference group after excluding transplantations with associating another organ $(n=67)$, split liver graft $(\mathrm{n}=55)$, pediatric donor $(\mathrm{n}=2)$ or donor after cardiac death $(\mathrm{n}=12)$.

The study was conducted in accordance with the Declaration of Helsinki (as revised in 2013). The study received approval from local ethics committee (comite d'éthique du CHU de Rennes NO21.49) and nonopposition consent was obtained from all participants.

\section{Surgical procedure and postoperative care}

After standard (with systematic donor vessels) procurement, liver grafts were usually preserved with Celsior ${ }^{\circledR}$ (before 2016) or custodiol ${ }^{\circledR}$ (after 2016).

All patients had orthotopic LT with inferior vena cava preservation. Briefly, after standard wound incision and exposition, the liver pedicle was first dissected. The native liver was removed and careful hemostasis was performed. Graft implantation started with a side-toside caval anastomosis followed by an end-to-end portal vein anastomosis. The graft was then vascularized prior to arterial anastomosis which was usually an end-to-end anastomosis between the recipient's proper HA (at the junction between the left and right branch) and the graft's common artery in order to have the largest anastomosis surface and the shortest length. The biliary anastomosis was usually performed by an end-to-end anastomosis between the main bile duct of the recipient and the graft intubated with a T-tube.

Regarding the arterial anastomosis, the decision to not use recipient HA was made preoperatively in case of known thrombosis or decided intraoperatively by the surgeon after evaluation of the quality of the HA and its flow. The choice of an alternative arterial site was also made by the surgeon according to his or her preferences. The SA anastomosis was performed in a side-to-end fashion while the CT anastomosis was performed in an end-to-end fashion with preservation of the splenic and gastric vessel when possible (Figure 2). When use of a conduit was required, allograft (usually the donor's iliac vessels) was preferred. In case of massive arteriosclerosis or insufficient length, a vascular prosthesis $\left(\right.$ Gore Tex $^{\circledR}$ ) was used. After arterial declamping, arterial flow was systematically evaluated by intraoperative Doppler ultrasonography with calculation of resistivity index.

After the procedure, aspirin was systematically administered as soon as possible as well as standardized immunosuppression (associating calcineurin inhibitor, 


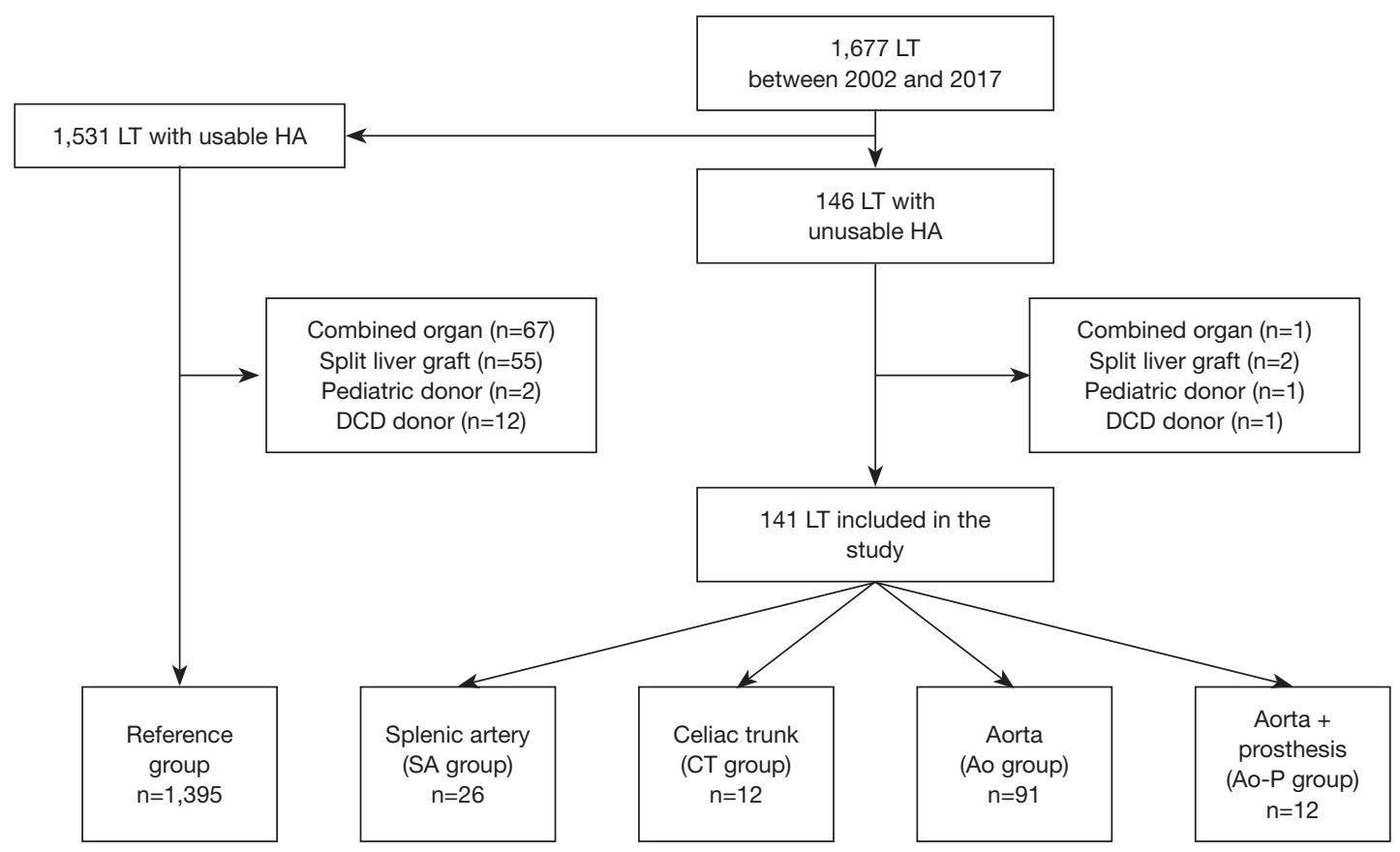

Figure 1 Flow chart. DCD, donation after circulatory death; HA, hepatic artery; LT, liver transplantation.
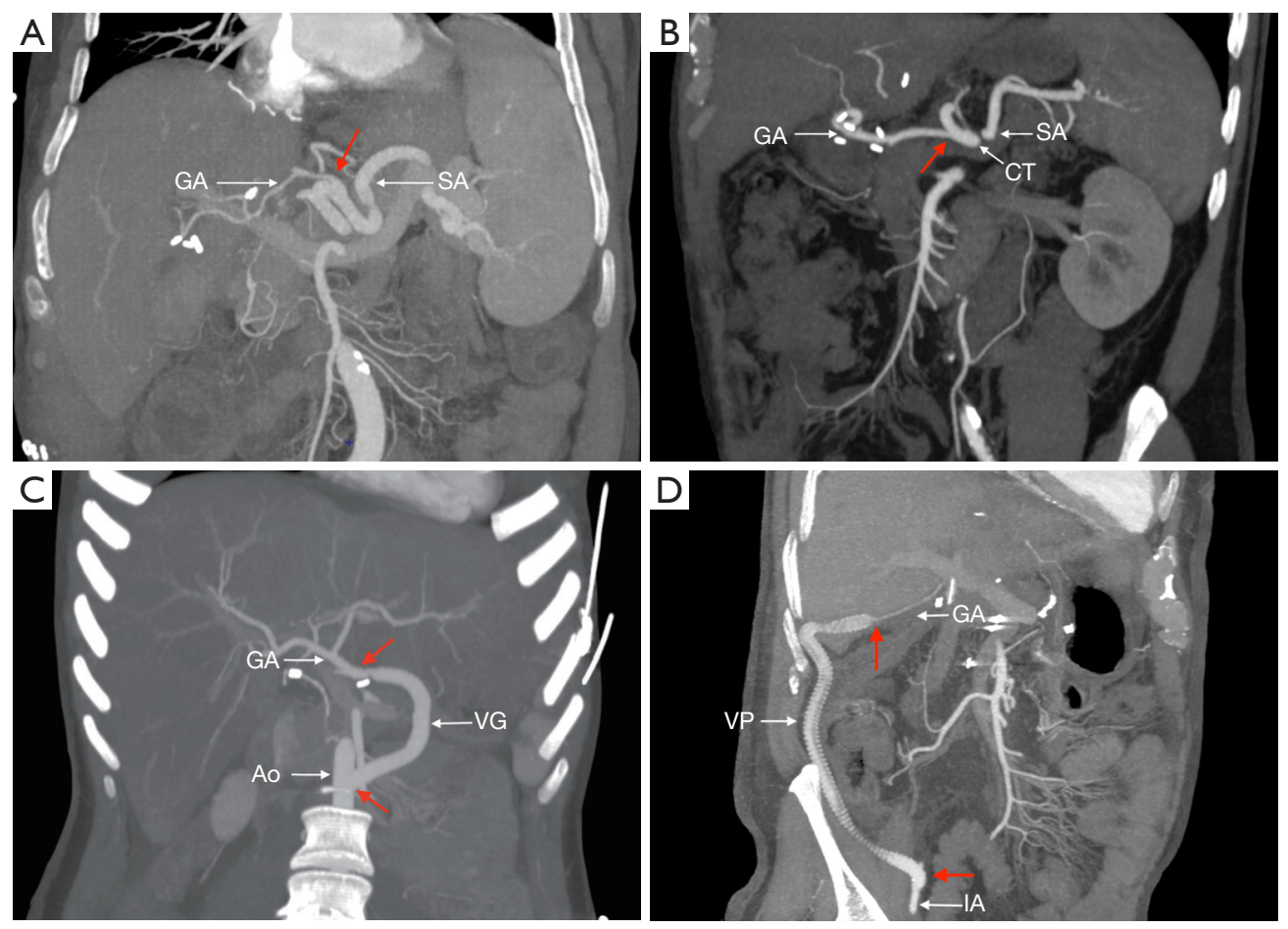

Figure 2 Arterial anastomosis using alternative implantation site on recipient. (A) Side-to-end anastomosis on recipient's splenic artery; (B) end-to-end anastomosis on celiac trunk with preservation of left gastric and splenic artery; (C) implantation on recipient's aorta using vascular graft (donor's iliac vessel); (D) implantation on recipient's right iliac artery using a vascular prosthesis. Red arrow: anastomosis site. Ao, recipient aorta; CT, coeliac trunk; GA, graft artery; IA, iliac artery; SA, splenic artery; VG, vascular graft (donor's iliac vessel); VP, vascular prosthesis. 
usually tacrolimus, mycophenolate mofetil and a short course of corticosteroids).

Systematic doppler ultrasonography was performed on postoperative days (POD) 1 and 7 and if hepatic dysfunction or vascular complication was suspected. When suspected, computed tomography was performed to confirm vascular complications and treatment (medical, radiological or surgical) was discussed in multidisciplinary meetings. Arterial thrombosis occurring before POD7 were operated for urgent revascularization, while thrombosis occurring after this period were followed (when asymptomatic) and listed for retransplantion when they became symptomatic (mostly biliary complications). Arterial stenosis was treated by radiological intervention.

No significant modification regarding the surgical procedure or postoperative medical care was observed during the study period.

\section{Clinical and biological parameter collection}

Clinical and biological data were retrospectively collected from a prospective database. The following parameters were analyzed:

* Donor and recipient demographic data (age, sex and BMI), MELD score, primary LT or retransplantation, use of an extended criteria donor (ECD) graft (defined by the presence of at least one of the following criteria: age $>65$ years; BMI $>30$; ICU stay $>7$ days prior procurement; natremia $>155 \mathrm{mmol} / \mathrm{L}$; liver enzymes 3 times higher the normal value (i.e., aspartate aminotransferase (ASAT) blood level $>150 \mathrm{IU} / \mathrm{mL}$, alanine aminotransferase (ALAT) blood level $>170 \mathrm{IU} / \mathrm{mL}$ ) and cause of donor death;

* Intraoperative data: cold ischemia time, delay to arterialization (defined as the time between portal and arterial revascularization), operative time, transfusion, and cause of unusable recipient HA;

* Postoperative data: incidence of arterial complications, duration of hospitalization, ClavienDindo classification, patient and graft survival;

- Biological data: incidence of early allograft dysfunction (EAD) defined according to Olthoff et al. (13) and evolution of liver function and creatinine level during the $7^{\text {th }}$ POD.

\section{Statistical analysis}

Comparative statistical analysis was made between the four study groups in order to compare them.

Quantitative variables were expressed as median with extreme values and compared using the Kruskal-Wallis test. Qualitative variables were expressed as number and percentage and compared using the chi-squared test. Survival analysis was performed with Kaplan-Meier curves and compared with the log-rank test. Repeated-measures analysis (i.e., evolution of biological parameters) during the early postoperative course was performed using a linear mixed-effects model (14).

All statistical analyses were performed with $\mathrm{R}$ software version 3.4.3. using the lme4 package version 1.1 .15 for linear mixed-effects analysis. A $\mathrm{P}<0.05$ value was considered to be statistically significant.

\section{Results}

\section{Population characteristics (Table 1)}

During the study period, 1,677 LT were performed at our center. After the selection process, 141 (8.4\%) LT performed with unusable recipient HA, were analyzed. The SA (SA group) was used in $26(18.4 \%)$ cases, the CT (CT group) in $12(8.5 \%)$ cases, the aorta (Ao group) in 91 $(64.5 \%)$ cases and the aorta with use of a vascular prosthesis (Ao-P group) in $12(8.5 \%)$ cases (Figure 1). Median age was $54[17-73]$ years with $65.2 \%(\mathrm{n}=92)$ men without differences between the groups.

In 74 cases (52.5\%), the procedure was a retransplantation (occurring after a median delay of 7.6 months and in 20 (37\%) cases within the first month) and was secondary to arterial thrombosis in 36 cases (49\%).

The median MELD score was 18.5 without significant differences between the groups.

The cause for not using recipient HA was reduced caliber or insufficient flow in 54 (35.1\%) cases, HAT in $79(59.4 \%)$ cases and intimal dissection in $8(5.5 \%)$ cases.

In the Ao group, the implantation site on the aorta was infrarenal in $57 \%(\mathrm{n}=52)$, supraceliac in $36 \%(\mathrm{n}=33)$ and on the iliac artery in $6 \%(\mathrm{n}=6)$. A conduit was used in $61.5 \%$ $(\mathrm{n}=56)$. In the Ao-P group, implantation was on the infrarenal aorta in $50 \%(\mathrm{n}=6)$, supraceliac in $8 \%(\mathrm{n}=1)$ and on the iliac artery in $42 \%(n=5)$. Median follow-up was 61 months for the entire cohort.

The reference group (i.e., using the recipient HA) consisted on 1,395 patients and as expected present major differences compared to the four study groups especially regarding rate of retransplantation. 
Table 1 Patient and donor characteristics

\begin{tabular}{|c|c|c|c|c|c|c|}
\hline Variables & SA group ( $n=26)$ & CT group $(n=12)$ & Ao group $(n=91)$ & Ao-P group ( $n=12)$ & $P$ value & $\begin{array}{l}\text { Reference group } \\
\quad(n=1,395)\end{array}$ \\
\hline \multicolumn{7}{|l|}{ Recipient characteristic } \\
\hline Gender (male) & $16(61.5 \%)$ & $9(75 \%)$ & $59(64.8 \%)$ & $8(66.7 \%)$ & 0.87 & $1,079(77.3 \%)$ \\
\hline Age (years) & 58 [19-66] & 56.5 [32-67] & 52 [17-73] & 54.5 [38-65] & 0.10 & 57 [15-73] \\
\hline MELD & 18 [6.5-37.9] & $13.7[6.4-40]$ & 19 [5.8-40] & $22.1[17.1-37.1]$ & 0.1 & $15[5.4-40]$ \\
\hline Creatinine $(\mu \mathrm{mol} / \mathrm{L})$ & $81[43-241]$ & 69 [59-175] & 89 [37-636] & 91 [53-200] & 0.32 & 74 [28-787] \\
\hline Dialysis & $1(3.8 \%)$ & $0(0 \%)$ & $7(7.7 \%)$ & $1(8.3 \%)$ & 0.70 & $29(2.1 \%)$ \\
\hline Retransplantation rate & $13(50 \%)$ & $3(25 \%)$ & $54(59.3 \%)$ & $4(33.3 \%)$ & 0.07 & $86(6.1 \%)$ \\
\hline Dissection & $6(23.1 \%)$ & 0 & $2(2.2 \%)$ & 0 & & NA \\
\hline \multicolumn{7}{|l|}{ Donor characteristics } \\
\hline Gender (male) & $15(57.7 \%)$ & $9(75 \%)$ & $53(58.2 \%)$ & $8(66.7 \%)$ & 0.68 & $811(58.1 \%)$ \\
\hline Age & 44.5 [20-86] & 53 [11-82] & $48[14-80]$ & 58.5 [16-79] & 0.37 & 55 [10-93] \\
\hline BMI & 23.44 [16.9-39.8] & 24.20 [18.1-31.6] & $23.05[16.1-32]$ & 27.21 [19.6-32.5] & 0.37 & 24.69 [13.9-54.4] \\
\hline ECD graft & $16(61.5 \%)$ & $6(50 \%)$ & $51(56 \%)$ & $8(66.7 \%)$ & 0.81 & $881(63.2 \%)$ \\
\hline Cause of donor death & & & & & 0.83 & \\
\hline 2002-2007 & $10(15 \%)^{*}$ & $2(3 \%)^{*}$ & $46(71 \%)^{*}$ & $7(11 \%)^{*}$ & & 472 (100\%) \\
\hline 2008-2012 & $9(19 \%)^{\star}$ & $4(8.5 \%)^{*}$ & $30(64 \%)^{*}$ & $4(8.5 \%)^{\star}$ & & $393(100 \%)$ \\
\hline 2013-2017 & $7(24 \%)^{\star}$ & $6(21 \%)^{*}$ & $15(52 \%)^{*}$ & $1(3 \%)^{\star}$ & & $530(100 \%)$ \\
\hline Follow up (months) & 70 [0-188.5] & 32.6 [0.1-184.3] & 62 [0-192.3] & 30.1 [0.9-192.9] & 0.59 & $61.3[0-205.9]$ \\
\hline
\end{tabular}

\section{Intraoperative outcomes (Table 2)}

Median operative time was 405 minutes and was close to being significantly increased in the Ao-P group with a median duration of $437.5 \mathrm{~min}(\mathrm{P}=0.05)$. No differences were noted regarding cold and warm ischemia times.

The median number of transfused red blood cell units was significantly increased in the Ao and Ao-P groups (8.5 and 16 respectively, $\mathrm{P}=0.002$ ). In the same way, the 
Table 2 Intraoperative and postoperative outcomes

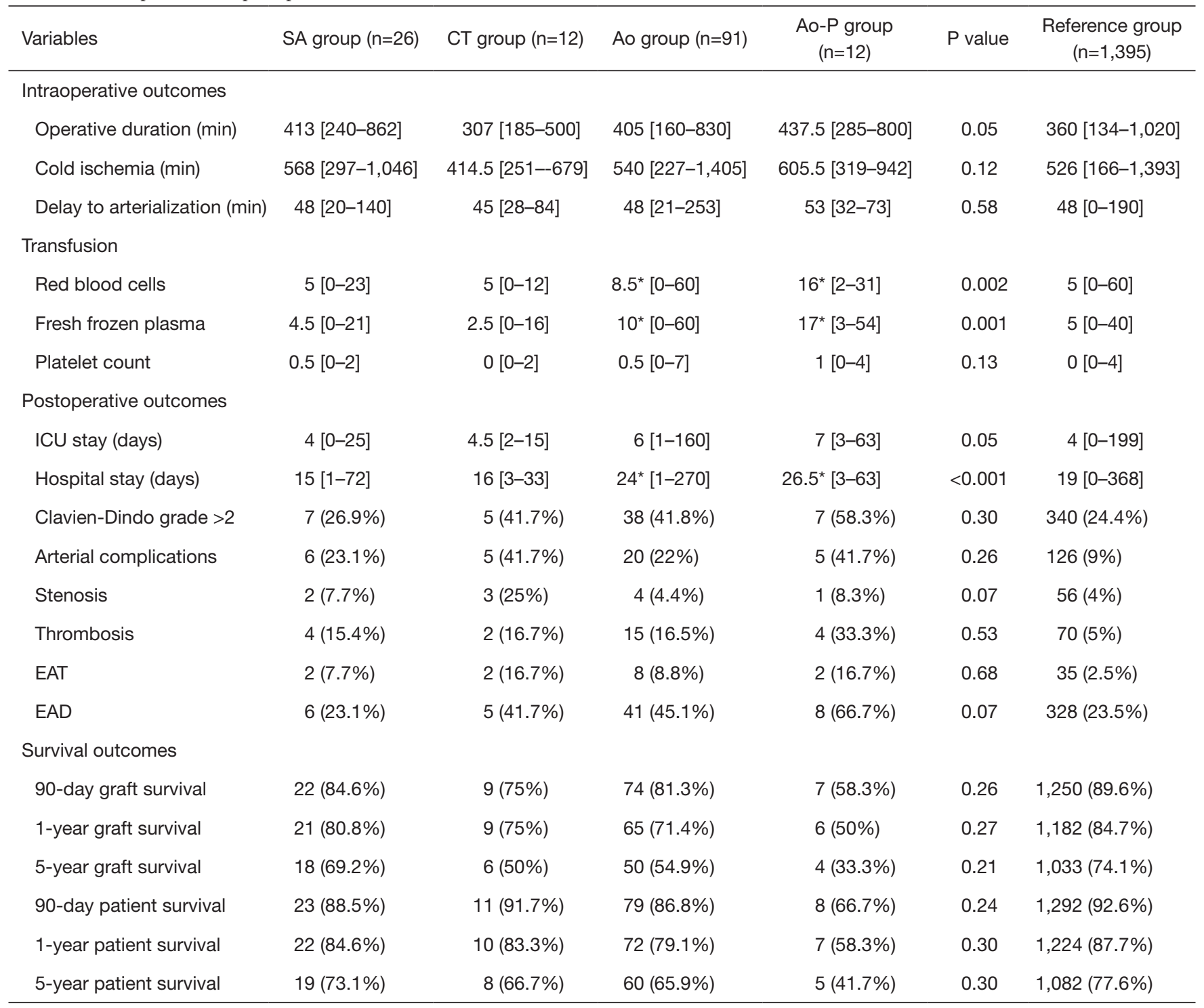

*, significantly different. Ao, aorta group; Ao-P, aorta + vascular prosthesis; CT, celiac trunk; ICU, intensive care unit; EAD, early allograft dysfunction; EAT, early artery thrombosis (<30 days); SA, splenic artery.

median number of transfused frozen plasma units was significantly increased in the Ao and Ao-P groups (10 and 17 respectively, $\mathrm{P}=0.001)$.

\section{Evolution of biological parameters (Figure 3)}

While the evolution of liver enzyme levels was not statistically different between the four study groups, linear mixed-effect analysis revealed that bilirubin levels were significantly increased in the Ao group $(\mathrm{P}=0.03)$ compared with the SA group and INR and factor V level were significantly increased in the Ao- $\mathrm{P}$ group $(\mathrm{P}=0.04$ and $\mathrm{P}=0.007$ respectively) compared with the SA group (Table 3).

Accordingly, the EAD rate was $23.1 \%$ in the SA group, $41.7 \%$ in the CT group, $45.1 \%$ in the Ao group and $66.7 \%$ in the Ao-P group, but without a significant difference $(\mathrm{P}=0.07)$. However, the creatinine level [which was similar preoperatively (Table 1)] was significantly increased in both the Ao $(\mathrm{P}=0.007)$ and Ao-P groups $(\mathrm{P}=0.008)$ compared with the SA group (Table 3). 

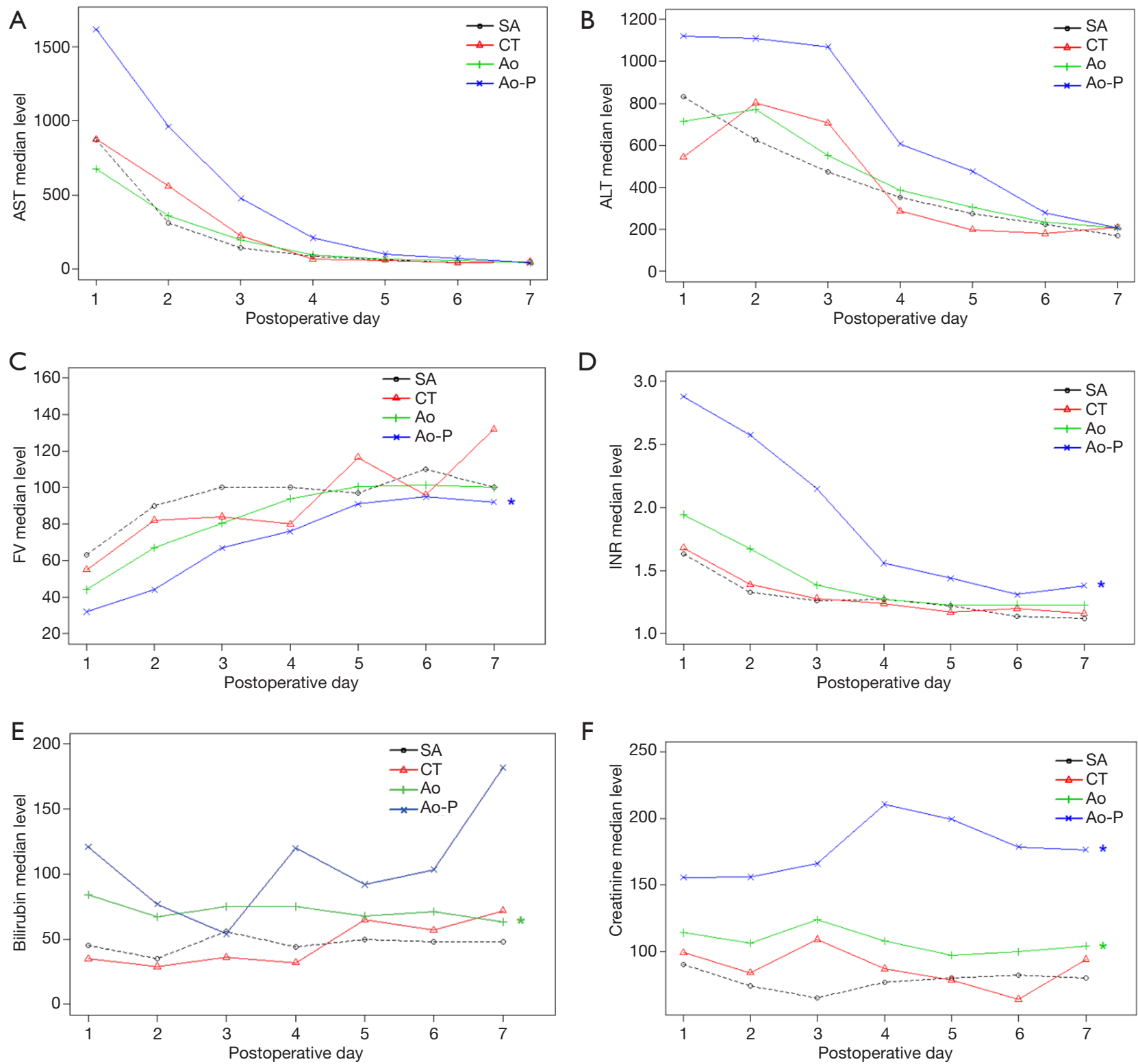

Figure 3 Biological parameter evolution. (A) AST level; (B) ALT level; (C) factor V level; (D) INR level; (E) total bilirubin level; (F) serum creatinine level. The * symbol means a significant difference compared with the splenic artery group. SA, splenic artery; CT, coeliac trunk; Ao, aorta group; Ao-P, aorta + vascular prosthesis group; AST, aspartate aminotransferase; ALT, alanine aminotransferase; INR, international normalized ratio.

\section{Postoperative outcomes (Table 2)}

Hospitalization duration was significantly higher in the Ao and Ao-P groups (24 and 26.5 days respectively, $\mathrm{P}<0.001$ ). The incidence of significant complications (i.e., ClavienDindo grade $>2$ ) was observed in $26.9 \%$ in the SA group, $41.7 \%$ in the CT group, $41.8 \%$ in the Ao group and $58.3 \%$ in the Ao-P group, without significant differences $(\mathrm{P}=0.3)$.
Overall, $36(25.5 \%)$ recipients had an arterial event (stenosis and/or thrombosis) without a difference between groups ( $\mathrm{P}=0.26)$. Early HAT (i.e., $<30 \mathrm{POD}$ ) rate was $7.7 \%$, $16.7 \%, 8.8 \%$ and $16.7 \%$ for the SA, CT, Ao and Ao-P groups respectively $(\mathrm{P}=0.68)$.

The 1-year graft and patient survival rate was $80.8 \%$ and $84.6 \%$ for the SA group, $75 \%$ and $83 \%$ for the CT group, $71.4 \%$ and $79.1 \%$ for the Ao group and $50 \%$ and $58.3 \%$ 
Table 3 Analysis of biological parameter evolution during the first 7 postoperative days

\begin{tabular}{lc}
\hline Variables & Mixed linear model ( $P$ value $)$ \\
\hline AST level & \\
SA group (= reference) & \\
CT group & 0.15 \\
Ao group & 0.29 \\
Ao-P group & 0.51 \\
ALT level &
\end{tabular}

SA group (= reference)

CT group

Ao group

0.43

Ao-P group

0.51

Bilirubin level

SA group (= reference)

CT group

0.87

Ao group

0.03

Ao-P group

0.1

INR level

SA group (= reference)

CT group

Ao group

0.1

Ao-P group

0.04

Factor V level

SA group (= reference)

CT group

0.93

Ao group

0.05

Ao-P group

0.007

Creatinine level

SA group (= reference)

$\begin{array}{ll}\text { CT group } & 0.06\end{array}$

$\begin{array}{ll}\text { Ao group } & 0.007\end{array}$

Ao-P group $\quad 0.008$

SA, splenic artery; CT, celiac trunk; Ao, aorta group; Ao-P, aorta + vascular prosthesis group.

for the Ao- $\mathrm{P}$ group $(\mathrm{P}=0.27$ and $\mathrm{P}=0.30$, respectively). The cause of graft loss at 1-year was an hemorrhagic or vascular complication in $15 \%(\mathrm{n}=4)$ for SA group (resulting in patient death in 1 case), $25 \%(\mathrm{n}=3)$ for CT group (resulting in patient death in 0 case), $11 \%(n=10)$ in Ao group (resulting in patient death in 2 cases) and $16.7 \%(\mathrm{n}=2)$ in Ao-P group (resulting in patient death in 0 case) and a severe sepsis or multivisceral failure in $0 \%$ for SA group, $0 \%$ for CT group, 11\% ( $\mathrm{n}=10)$ for Ao group (resulting in patient death in 10 cases), $25 \%(\mathrm{n}=3)$ for Ao-P group (resulting in patient death in 3 cases), $\mathrm{P}=0.27$.

The 5-year graft and patient survival rate was $69.2 \%$ and $73.1 \%$ for the SA group, $50 \%$ and $66.7 \%$ for the CT group, $54.9 \%$ and $65.9 \%$ for the Ao group and $33.3 \%$ and $41.7 \%$ for the Ao-P group $(\mathrm{P}=0.21$ and $\mathrm{P}=0.30$, respectively). Long-term graft $(\mathrm{P}=0.18)$ and patient $(\mathrm{P}=0.16)$ survival was also not different (Figure 4).

When comparing with the reference group, the graft survival was significantly worst for $\mathrm{CT}$ group $(\mathrm{P}=0.02)$, Ao group $(\mathrm{P}=0.001)$ and Ao-P group $(\mathrm{P}<0.001)$ while it was not different for SA group $(\mathrm{P}=0.31)$. Regarding the patient's survival, there was a significant difference between the reference group and the Ao- $\mathrm{P}$ group $(\mathrm{P}=0.004)$ while it was not different for Ao group ( $\mathrm{P}=0.096)$, CT group $(\mathrm{P}=0.24)$ and $\mathrm{SA}$ group $(\mathrm{P}=0.61)$.

\section{Discussion}

During LT, HA reconstruction remains a technical challenge and complex arterial reconstruction (typically when recipient HA cannot be used) is a well-known risk factor of arterial thrombosis (14-17).

In the present study, we found that using the recipient SA or CT was associated with lower intraoperative transfusion rates and better graft function recovery, resulting in lower durations of hospitalization. On the other hand, implantation on the aorta using a vascular prosthesis as conduit was associated with higher intraoperative transfusions and worse postoperative graft and renal function resulting in longer stays in the intensive care unit and the hospital. However, we did not find a significant difference regarding the rate of arterial complications although the occurrence of arterial stenosis increased in the CT group $(25 \%, \mathrm{P}=0.08)$ and thrombosis in the Ao-P group $(33.3 \%, \mathrm{P}=0.53)$. In the same way, we did not find a significant difference regarding graft or patient survival between the four study groups although visual analysis of the Kaplan-Meier curves suggests a worse outcome with a vascular prosthesis. This absence of statistical significance is probably due to the limited number of patients in the different groups, resulting in a lack of power. However, 
A

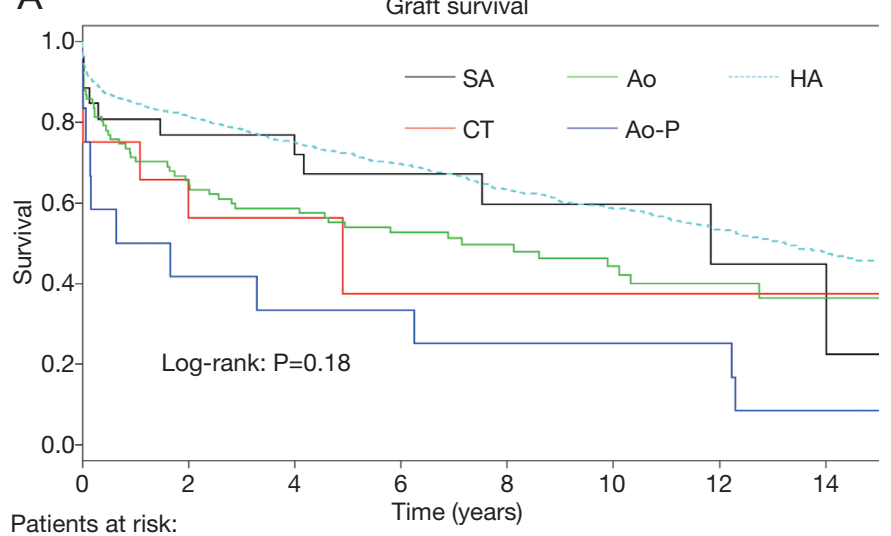

Patients at risk:

SA $26 \quad 18$

CT 12

Ao 91

Ao-P 12

HA 1,395 1,069

$\begin{array}{ccccccc}16 & 12 & 8 & 4 & 3 & 2 & \mathrm{SA} \\ 3 & 2 & 2 & 1 & 1 & 1 & \mathrm{CT} \\ 50 & 40 & 30 & 21 & 15 & 5 & \mathrm{~A} \\ 4 & 4 & 3 & 3 & 3 & 1 & \mathrm{~A}\end{array}$

B

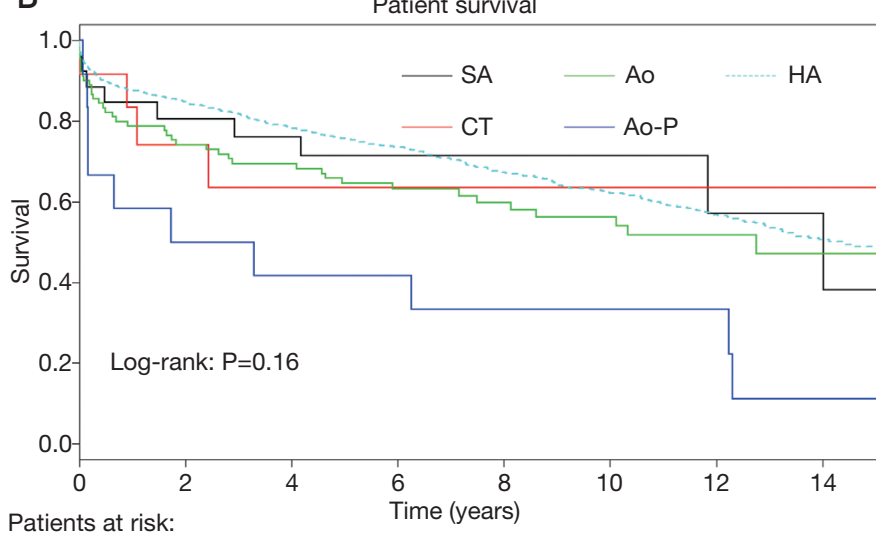

Patients at risk:

SA 26

Ao 91

Ao-P 12

HA 1,395

$\begin{array}{cc}19 & 16 \\ 8 & 3 \\ 64 & 56 \\ 6 & 5 \\ 109 & 844\end{array}$

$1,109 \quad 844$

$\begin{array}{ccccc}13 & 10 & 6 & 4 & 3 \\ 3 & 3 & 1 & 1 & 1 \\ 44 & 34 & 26 & 15 & 5 \\ 5 & 4 & 3 & 3 & 1 \\ 635 & 457 & 324 & 210 & 106\end{array}$

Figure 4 Long-term graft (A) and patient (B) survival. SA, splenic artery; CT, coeliac trunk; Ao, aorta group; Ao-P, aorta + vascular prosthesis group; HA, hepatic artery.

when comparing with the reference group's ( $n=1,395)$ outcome, only patients in the SA group shown similar outcomes. Indeed, the CT, Ao and Ao-P group presented worst graft survival while the Ao-P group also presented worst patient survival.

Typically, when a recipient HA is unusable, the preferred arterial implantation site is the aorta with use of the donor iliac vessels as conduits if needed (18-20). Recently in a systematic review, Reese et al. (21) found that this option was associated with a higher incidence of early arterial thrombosis ( $7 \%$ vs. $2 \%, \mathrm{P}=0.001)$ as well as worse grafts (HR $=1.38, \mathrm{P}<0.001)$ and patient survival $(\mathrm{HR}=1.57, \mathrm{P}=0.009)$ compared with the non-conduit groups. In their study, they reported 5-year survival at 54\% and $67 \%$ for grafts and patients respectively which is similar to our findings with 5 -year survival at $54.9 \%$ and $65.9 \%$ for grafts and patients respectively. Moreover, we found that these results were even worse with vascular prosthesis instead of allograft with 5 -year survival at $33.3 \%$ and $41.7 \%$ for grafts and patients respectively. Even if it did not reach significance, we believe that our findings plead for avoiding this method if possible and explain the decrease rate of Ao or Ao-P anastomosis performed during the study period contrary to SA and CT (Table 1).

Other authors have described alternative implantation sites such as the CT $(8,9,22)$ or SA $(5,10,11,23,24)$ with interesting results (Table 4). Indeed, El-Hinnawi et al. (9) reported a series of 9 cases ( 5 pediatric and 4 adults) using the CT without major postoperative complications. Dokmak et al. (8) reported a series of 7 patients using CT. In their study, one patient died in the early postoperative course and among the 6 remaining patients, patent arterial flow was found in $100 \%$ with a follow-up of 6 to 15 months. Stange et al. (5) reported a series of 133 anastomoses on the SA with $0.8 \%$ HAT. Figueras et al. (11) reported a series of 23 patients using the SA and reported 3-year graft and patient survival of $72 \%$ and recently, Llado et al. (26) reported a series of 54 patients using SA and found comparable outcomes to those having a standard HA reconstruction. Our results are in line with previous reports with similar favorable intraoperative and postoperative outcomes when using SA or CT (Table 4). However, the long-term outcomes in our study appear to be in favor of using SA instead of CT in term or arterial complications.

Indeed, the SA artery is usually dilated owing to frequent splenomegaly in cirrhotic patients and can be easily controlled after its emergence above the pancreatic head, thereby representing a safe and good alternative for arterial anastomosis. On the contrary, control of the supraceliac or infrarenal aorta could be difficult in cirrhotic patients owing to concurrent portal hypertension especially in obese recipients. Therefore, avoiding aortic clamping and unnecessary dissection (leading to less bleeding and transfusion) could represent an additional benefit by preserving recipient hemodynamics, which could already be unstable after graft revascularization, and reducing 
Table 4 Main studies reporting alternative arterial implantation site outcome

\begin{tabular}{|c|c|c|c|c|}
\hline Reference & Implantation site & EAT (\%) & Graft survival & Patient survival \\
\hline \multirow[t]{2}{*}{ Figueras et al., (11) [1997] } & SA: 23 & 0 & $78 \%$ at 1 -year; $72 \%$ at 3 -year & $78 \%$ at 1 -year; $72 \%$ at 3 -year \\
\hline & Ao: 12 & 17 & $74 \%$ at 1 -year; $74 \%$ at 3 -year & $80 \%$ at 1 -year; $80 \%$ at 3 -year \\
\hline Stange et al., (5) [2003] & SA: 133 & 0.8 & - & - \\
\hline D’Albuquerque et al., (24) [2007] & SA: 4 & 0 & - & - \\
\hline Vanderlan et al., (12) [2008] & SA: 7 & 14 & $86 \%$ at 9 -month & $100 \%$ at 9 -month \\
\hline El-Hinnawi et al., (9) [2013] & CT: 9 & 0 & $83 \%$ at $1,3,5$ years & $83 \%$ at $1,3,5$ years \\
\hline Dokmak et al., (8) [2015] & CT: 7 & 0 & - & $86 \%$ at 15 -month \\
\hline \multirow[t]{2}{*}{ Kazemi et al., (25) [2017] } & SA: 17 & - & $88 \%$ at 1 -year; $82 \%$ at 5 -year & $94 \%$ at 1 -year; $88 \%$ at 5 -year \\
\hline & Ao: 76 & - & $78 \%$ at 1 -year; $62 \%$ at 5 -year & $97 \%$ at 1 -year; $69 \%$ at 5 -year \\
\hline Llado et al., (26) [2019] & SA: 54 & 3.7 & $64 \%$ at 5 -year & $67 \%$ at 5-year \\
\hline \multirow[t]{4}{*}{ Beaurepaire et al., [2019] } & SA: 26 & 7.7 & $80 \%$ at 1 -year; $69 \%$ at 5 -year & $84 \%$ at 1 -year; $73 \%$ at 5 -year \\
\hline & CT: 12 & 16.7 & $75 \%$ at 1 -year; $50 \%$ at 5 -year & $83 \%$ at 1 -year; $67 \%$ at 5 -year \\
\hline & Ao: 91 & 8.8 & $71 \%$ at 1 -year; $55 \%$ at 5 -year & $79 \%$ at 1 -year; $65 \%$ at 5 -year \\
\hline & Ao-P: 12 & 16.7 & $50 \%$ at 1 -year; $33 \%$ at 5 -year & $58 \%$ at 1 -year; $41 \%$ at 5 -year \\
\hline
\end{tabular}

Ao, aorta group; Ao-P, aorta + vascular prosthesis; CT, celiac trunk; EAT, early artery thrombosis ( $<30$ days); SA, splenic artery.

delay between portal and arterial revascularization as well as operative time (25). These benefits could explain the improved graft and kidney function observed in the SA and CT groups during the postoperative course.

Thus, if preoperative imaging is compatible, we believe that SA or CT should be considered firstly, instead of implantation on aorta like stated by other authors (7).

Our results must be interpreted with caution. First, the retrospective nature of the study and the arbitrary decision of the surgeon regarding the choice of the arterial site inevitably induce a methodological and selection bias although there was no difference regarding the demographic data. Moreover, the limited population size (with a large majority in group Ao) as well as the analysis of 4 different groups led to a lack of power that could explain the absence of significant differences especially regarding survival outcomes or arterial complications.

To our knowledge, the present study is the largest monocentric study $(n=141)$ that compares all alternative arterial sites of anastomosis along with the largest series using a aorto-hepatic conduit with a vascular prosthesis $(n=12)(6,27-29)$. Therefore, our study represents the "reallife" practice of a high volume LT center. Moreover, our results are in line with the other reports from previous studies which strengthened our findings (Table 4). In addition, our study is the first to analyze and report the postoperative biological parameters of graft and kidney function which should also be interpreted with cautious since it may be influenced by multiple factors.

In any case, our results must be confirmed in a larger multicentric series since a prospective randomized study may be difficult to set up.

In conclusion, we believe that using the SA or the CT (despite an elevated stenosis rate in our series) is a safe and efficient alternative. When an aorto-hepatic anastomosis should be performed, use of a vascular prosthesis must be avoided if possible. Our results must be confirmed in a larger series. 


\section{Acknowledgments}

This work was presented as a poster communication at the Congress of the French Association of Hepato-Biliary and Transplantation Surgery (ACHBT) in Marne-la-Vallée, France in 2018.

Funding: None.

\section{Footnote}

Reporting Checklist: The authors have completed the STROBE reporting checklist. Available at https://hbsn. amegroups.com/article/view/10.21037/hbsn-20-10/rc

Data Sharing Statement: Available at https://hbsn. amegroups.com/article/view/10.21037/hbsn-20-10/dss

Conflicts of Interest: All authors have completed the ICMJE uniform disclosure form (available at https://hbsn. amegroups.com/article/view/10.21037/hbsn-20-10/coif). GBLS serves as an unpaid editorial board member of Hepatobiliary Surgery and Nutrition. The other authors have no conflicts of interest to declare.

Ethical Statement: The authors are accountable for all aspects of the work in ensuring that questions related to the accuracy or integrity of any part of the work are appropriately investigated and resolved. The study was conducted in accordance with the Declaration of Helsinki (as revised in 2013). The study received approval from local ethics committee (comité d'éthique du CHU de Rennes NO21.49) and non-opposition consent was obtained from all participants.

Open Access Statement: This is an Open Access article distributed in accordance with the Creative Commons Attribution-NonCommercial-NoDerivs 4.0 International License (CC BY-NC-ND 4.0), which permits the noncommercial replication and distribution of the article with the strict proviso that no changes or edits are made and the original work is properly cited (including links to both the formal publication through the relevant DOI and the license). See: https://creativecommons.org/licenses/by-nc-nd/4.0/.

\section{References}

1. Duffy JP, Hong JC, Farmer DG, et al. Vascular complications of orthotopic liver transplantation: experience in more than 4,200 patients. J Am Coll Surg
2009;208:896-903; discussion 903-5.

2. Tzakis AG, Gordon RD, Shaw BW Jr, et al. Clinical presentation of hepatic artery thrombosis after liver transplantation in the cyclosporine era. Transplantation 1985;40:667-71.

3. Mourad MM, Liossis C, Gunson BK, et al. Etiology and management of hepatic artery thrombosis after adult liver transplantation. Liver Transpl 2014;20:713-23.

4. Bekker J, Ploem S, de Jong KP. Early hepatic artery thrombosis after liver transplantation: a systematic review of the incidence, outcome and risk factors. Am J Transplant 2009;9:746-57.

5. Stange BJ, Glanemann M, Nuessler NC, et al. Hepatic artery thrombosis after adult liver transplantation. Liver Transpl 2003;9:612-20.

6. Muralidharan V, Imber C, Leelaudomlipi S, et al. Arterial conduits for hepatic artery revascularisation in adult liver transplantation. Transpl Int 2004;17:163-8.

7. Hibi T, Nishida S, Levi DM, et al. Long-term deleterious effects of aortohepatic conduits in primary liver transplantation: proceed with caution. Liver Transpl 2013;19:916-25.

8. Dokmak S, Aussilhou B, Landi F, et al. The recipient celiac trunk as an alternative to the native hepatic artery for arterial reconstruction in adult liver transplantation. Liver Transpl 2015;21:1133-41.

9. El-Hinnawi A, Nishida S, Levi D, et al. Use of the recipient celiac trunk for hepatic artery reconstruction in orthotopic liver transplantation. Transplant Proc 2013;45:1928-30.

10. Cherqui D, Riff $Y$, Rotman N, et al. The recipient splenic artery for arterialization in orthotopic liver transplantation. Am J Surg 1994;167:327-30.

11. Figueras J, Parés D, Aranda H, et al. Results of using the recipient's splenic artery for arterial reconstruction in liver transplantation in 23 patients. Transplantation 1997;64:655-8.

12. Vanderlan WB, Abouljoud MS, Yoshida A, et al. Experience with recipient splenic artery inflow in adult liver transplantation: a case series. Cases J 2008;1:82.

13. Olthoff KM, Kulik L, Samstein B, et al. Validation of a current definition of early allograft dysfunction in liver transplant recipients and analysis of risk factors. Liver Transpl 2010;16:943-9.

14. Davidian M, Giltinan DM. Nonlinear models for repeated measurement data: An overview and update. J Agric Biol Environ Stat 2003;8:387-419.

15. Oberkofler CE, Reese T, Raptis DA, et al. Hepatic artery 
occlusion in liver transplantation: What counts more, the type of reconstruction or the severity of the recipient's disease?. Liver Transpl 2018;24:790-802.

16. Herrero A, Souche R, Joly E, et al. Early Hepatic Artery Thrombosis After Liver Transplantation: What is the Impact of the Arterial Reconstruction Type? World J Surg 2017;41:2101-10.

17. Yang Y, Zhao JC, Yan LN, et al. Risk factors associated with early and late HAT after adult liver transplantation. World J Gastroenterol 2014;20:10545-52.

18. Shaked AA, Takiff H, Busuttil RW. The use of the supraceliac aorta for hepatic arterial revascularization in transplantation of the liver. Surg Gynecol Obstet 1991;173:198-202.

19. Shaw BW Jr, Iwatsuki S, Starzl TE. Alternative methods of arterialization of the hepatic graft. Surg Gynecol Obstet 1984;159:490-3.

20. Oberkofler CE, Raptis DA, DiNorcia J, et al. How to Handle Arterial Conduits in Liver Transplantation? Evidence From the First Multicenter Risk Analysis. Ann Surg 2020. [Epub ahead of print].

21. Reese T, Raptis DA, Oberkofler CE, et al. A systematic review and meta-analysis of rescue revascularization with arterial conduits in liver transplantation. Am J Transplant 2019;19:551-63.

22. Kalayoglu M, Belzer FO. A new technique for arterialization of the hepatic graft. Surg Gynecol Obstet 1987;164:564-7.

Cite this article as: Beaurepaire JM, Orlando F, Levi Sandri GB, Jezequel C, Bardou-Jacquet E, Camus C, Lakehal M, Desfourneaux V, Merdrignac A, Gaignard E, Thobie A, Bergeat D, Meunier B, Rayar M. Comparison of alternative arterial anastomosis site during liver transplantation when the recipient's hepatic artery is unusable. HepatoBiliary Surg Nutr 2022;11(1):1-12. doi: 10.21037/hbsn-20-10
23. Katz E, Fukuzawa K, Schwartz M, et al. The splenic artery as the inflow in arterial revascularization of the liver graft in clinical liver transplantation. Transplantation. 1992;53:1373-4.

24. D'Albuquerque LA, Gonzalez AM, Letrinda RF, et al. Use of the splenic artery for arterial reconstruction in living donor liver transplantation. Transplant Proc 2007;39:3202-3.

25. Kazemi K, Samidoost P, Deilami HN, et al. A New Consideration in Hepatic Artery Reconstruction in Adult Liver Transplant: Arterial Transposition Versus Extra-Anatomic Jump Grafts. Exp Clin Transplant 2017;15:204-7.

26. Llado L, Ramos E, Bravo A, et al. Short- and longterm outcomes of arterial reconstruction on recipient splenic artery in adult liver transplantation. Single-center prospective study 25 years after first description. Transpl Int 2019;32:1053-60.

27. Liu T, Dilworth P, Sosef M, et al. Arterial vascular conduits in adult orthotopic liver transplant recipients. ANZ J Surg 2006;76:64-7.

28. Mosna LC, Moon J, Hernandez F, et al. Use of the subcutaneous route and polytetrafluoroethylene grafts for arterial revascularization in liver transplantation. Liver Transpl 2012;18:499-500.

29. Chedid MF, Grezzana-Filho TJ, Chedid AD, et al. Liver Transplantation Utilizing Mixed Biologic and Synthetic Arterial Conduits. Case Rep Surg 2016;2016:9245079. 